\title{
Forecasting Natural Gas Demand in a Region with Seven Models and Evaluating Their Accuracy Using As Criteria Five Types of Errors/Residuals
}

\author{
${ }^{1}$ E. Stathakis, ${ }^{2}$ E. Stambologlou ${ }^{*}$ \\ ${ }^{1}$ Diploma of Mechanical Engineer P\&A, M.Sc. in Advance Information Systems, a PhD Candidate in \\ Economy of Energy \\ ${ }^{2}$ Diploma of Surveyor Engineer (NTUA 1984), M.Sc. in System Engineering and management, a PhD \\ candidate in Rural Infrastructures
}

\begin{abstract}
The modeling of Natural Gas (NG) demand differs significantly from the demand for electricity in terms of the determinants that affect it, as all fields of economic activities in a modern economy are directly related to electricity but not to NG. But NG is the second energy type after electricity used in all countries in percentages greater than $10 \%$ in average terms. NG is going to be installed in the Region of East Macedonia-Thrace (REMTH) the next years. So, we consider it is worth to predict the NG demand in REMTH using eight deterministic forecasting models. In order to do it we used a dataset of 20 years concerning two Greek regions to which the NG is used that period and through them we built the eight forecasting models aiming to find the NG demand in the REMTH. In order to evaluate the reliability and accuracy of them we used four types of statistical errors, Mean Error (ME), Mean Absolute Error (MAE), Mean Absolute Percentage Error (MAPE) and Mean Absolute Scale Error (MASE). These are the most widely used measures of evaluating the accuracy of deterministic predictive models, due to their advantages of scale-independency and interpretability. When each of them is used alone has the significant disad-vantage to produce infinite or undefined values for zero or close-to-zero actual values. In order to address this disadvantage, we propose a way to use the same time all of them measuring the accuracy of a model used to forecast the demand of Natural Gas in the Greek region EMTH. The innovation of this paper is that for NG demand forecasting were used seven different models and they are evaluated regarding their reliability /accuracy using five types of residuals or statistical errors.
\end{abstract}

Keywords: Natural Demand, forecasting models, evaluation of models, time series.

\section{Introduction to timeseries analysis and forecasting}

Mathematically a timeseries regarding the $\mathrm{NG}$ demand is defined by the function of $\mathbf{Y}_{\mathbf{n g}}=\mathbf{f}_{\mathbf{t}}\left(\mathbf{T}_{\mathbf{e d}}, \mathbf{I}_{\mathbf{c}}, \mathbf{T}_{\mathbf{e m}}, \mathbf{P}_{\mathbf{n g}}, \mathbf{P}_{\mathbf{e l}}, \mathbf{E}\right)$ where, $\mathbf{Y}_{\mathbf{n g}}$ is dependent variable, $\mathbf{I}_{\mathbf{c}}$ is income per capital, $\mathbf{P}$ the price of electricity and $\mathrm{NG}$ at times $\mathrm{t}_{1}, \mathrm{t}_{2}, \ldots \mathrm{t}_{\mathrm{n}}$ and $\mathrm{E}$ is elasticities. Therefore, $\mathrm{Y}$ is a function of $\mathrm{t}$, and this is denoted as $\mathrm{Y}=\mathrm{f}(\mathrm{t})$. The analysis of timeseries deals exclusively with the investigation of the overtime behavior of the values of a variable, the observations of which come from a timeseries. The forecast of future prices of the variable according to the timeseries analysis can come from the following categories of forecasting methods, Smoothing Methods, Timeseries Decomposition, ARIMA Analysis. The criteria for evaluating forecasting methods based on timeseries are used to select the appropriate method. These criteria are based on the values of the deviations of the predicted values from the corresponding real values of the time series. For a variable $\mathrm{Y}$, the deviation of the predicted value of Yt from the corresponding real value of Yt for the period $t$, where $t=1,2,3, \ldots, n$, is called forecast Error, is denoted by et and is defined as: $\mathbf{e}_{\mathbf{t}}=\mathbf{Y}_{\mathbf{t}}-\mathbf{Y}^{\prime}{ }_{\mathbf{t}}$.

To determine the reliability of a particular prediction of a statistical method, we need to study the overtime behavior of prediction error values. This is done by applying various criteria, according to which we evaluate the predicted method used. Each of these criteria is defined by a specific functional relationship of 
prediction errors and can be used not only to evaluate a prediction method but also to select the best one between two or more alternative prediction methods. These criteria are:

Mean Squared Error-MSE: is defined as the sum of the squares of the errors divided by the number of time periods n, in which predictions were made $\boldsymbol{M S E}=\frac{1}{n} \sum_{t=1}^{n}\left(y_{t}-\overline{y_{t}}\right)^{2}=\sum_{t=1}^{n} e_{t}^{2}$

Root Mean Squared Error-RMSE: is defined as the square root of MSE, so $R \boldsymbol{M S E}=\sqrt{\boldsymbol{M S E}}$

Mean Absolute Percentage Error-MAPE: is defined as the sum of the absolute values of the prediction errors to the corresponding real time values of the time series divided by the number of time periods $\mathrm{n}$, in which predictions were made. $\boldsymbol{M A P E}=\frac{1}{n} \sum_{t=1}^{n}\left|\boldsymbol{e}_{t}^{2}\right| / y_{t}$

Mean Percentage Error-MPE: we use it when we are interested in determine if the prediction method is biased, that is, if the predicted values are systematically greater or less than corresponding real. $M P E=\frac{1}{n} \sum_{t=1}^{n}\left|e_{t}^{1}\right| / y_{t}$

Mean Absolute Deviation-MAD: expresses the average value of the absolute deviations of the predicted values of the time series from the corresponding real ones and is based on the assumption that its severity is linearly related to the magnitude of the error. $M A D=\frac{1}{n} \sum_{t=1}^{n}\left|e_{t}^{1}\right|$

The timeseries analysis uses tree types for forecasting, the smoothing, the decomposition and the AutoRegressive Average .

$\mathbf{1}^{\text {st }}$ : Smoothing methods: are techniques that determine the future values of a variable based on how they are applied. Their creation predictions come from the smoothing of the time evolution of the values of the variable, in order to better recognize its mode of behavior. Some of the smoothing methods can also be applied to a small number of observations of the variable, $30 \leq$ like our case. The basic smoothing methods are, Simple Moving Average (MA), Simple Exponential Smoothing (SES), Double Moving Average (DMA), Brown, Holt and Winters. If the timeseries shows a trend pattern then we use the double exposure smoothing method, the Brown method, or the Holt method, while if the timeseries shows seasonality then we use the Winters method. If timeseries is stationary the appropriate method of predicting future prices is the method of move averages - MA.

The smoothing models follow the next formulas in brief:

- Simple Moving Average (MA): The predictions of a $Y t$ timeseries, for $t=1,2, \ldots, n$, are created by the MA method as follows, $\widehat{\boldsymbol{Y}}_{\boldsymbol{t}+\mathbf{1}}=\widehat{\boldsymbol{Y}}_{\boldsymbol{t}}+\boldsymbol{Y}_{\boldsymbol{t}} / \boldsymbol{m}+\boldsymbol{Y}_{\boldsymbol{t}-\boldsymbol{m}} / \boldsymbol{m}$, where $\mathbf{Y}_{\mathbf{t}+\mathbf{1}}$ is the forecast for the period $(\mathbf{t}+\mathbf{1})$ and $\mathbf{m}$ is the number of periods used to calculate the average value.

○ Simple Exponential Smoothing (SES): The $\dot{\boldsymbol{Y}}_{\boldsymbol{t}+\mathbf{1}}=\boldsymbol{a} \boldsymbol{Y}_{\boldsymbol{t}}+(\mathbf{1}-\boldsymbol{a}) \dot{\boldsymbol{Y}}_{\boldsymbol{t}}$ the mathematical expression of the SES method and is defined for $\mathrm{t}=2,3, \ldots, \mathrm{n}$ with initial condition $\dot{\boldsymbol{Y}}_{\mathbf{2}}=\boldsymbol{Y}_{\mathbf{1}}$. Applying the SES method to the time series observations for values of $\alpha$ from 0 to 1 we select that value of $\alpha$ that minimizes the value of the MSE criterion.

- Double Moving Average (DMA): To configure predictions with this method, a second moving average is calculated from the simple moving average, while in then the linear trend of the timeseries observations having the form $\hat{\boldsymbol{Y}}_{\boldsymbol{t}}+\boldsymbol{h}=\boldsymbol{a}_{\boldsymbol{t}}+\boldsymbol{h} \boldsymbol{b}_{\boldsymbol{t}}$, is also taken into account. This method can be used for $\boldsymbol{h}>\mathbf{1}$ to make predictions for more than one future periods, while for $\boldsymbol{h}=\mathbf{1}$ it gives the forecast for the next period. Of course, its use presupposes the existence of a larger number of observations, especially when the value of $\mathrm{m}$ is relatively large.

○ Brown or Double Exponential Smoothing (B-DES): The application of the method is based on the following procedure: $\mathbf{a}$. The initial observations of the timeseries are normalized $\mathbf{b}$. The smoothed values $\boldsymbol{A}_{\boldsymbol{t}}$ of the timeseries are complete smoothed c. The difference $\boldsymbol{a}_{\boldsymbol{t}}$ is calculated as: $\boldsymbol{a}_{\boldsymbol{t}}=\mathbf{2} \boldsymbol{A}_{\boldsymbol{t}}-$ $\boldsymbol{A}^{\prime}{ }_{\boldsymbol{t}}$ d. The adjustment factor for the $\boldsymbol{b}_{\boldsymbol{t}}$. e. trend is calculated. The prediction $\boldsymbol{Y}_{\boldsymbol{t}+\mathbf{1}}$ for the future $\mathbf{h}$ period is calculated by calculated $\quad \boldsymbol{Y}_{\boldsymbol{t}+\mathbf{1}}=\boldsymbol{a}_{\boldsymbol{t}}+\boldsymbol{h} \boldsymbol{b}_{\boldsymbol{t}}$ 
○ Holt or Exponential Smoothing for Trend Adaptation (H-ESTA): It has two parameters of smoothing, the a for smoothing the values of the timeseries and the $b$ for smoothing the trend. The Holt is based on the process of smoothing the values of the At timeseries, smoothing the trend $\mathbf{T t}$ and predicting $\boldsymbol{Y}_{\boldsymbol{t}+\boldsymbol{h}}$ for the future $\mathbf{h}$ period and is defined as: $\boldsymbol{Y}_{\boldsymbol{t}+\boldsymbol{h}}=\boldsymbol{A}_{\boldsymbol{t}}+\boldsymbol{h} \boldsymbol{T}_{\boldsymbol{t}}$, where $\mathrm{h}=1,2,3, \ldots$ The Holt method is more applicable in practice, as it has better results than the Brown method.

$\mathbf{2}^{\text {nd }}$ : Decomposition methods: identify the components of the available timeseries data in order to understand how they behave. The purpose of decomposition methods is to isolate these components as accurately as possible. The components are, trend $(\mathbf{T})$, cyclicity $(\mathbf{C})$, seasonality $(\mathbf{S})$ and randomness $(\mathbf{R})$. The trend (Tt) is defined as a long-term change of the average price level of the timeseries. In order to determine the trend, there must be a sufficient number of observations and at the same time the appropriate length of the period must be estimated.

The cyclic (Ct ) of a timeseries represents a wave change due to special exogenous conditions and occurs periodically. The periods are not constant and are usually greater than one year. The timeseries of more economical sizes such as GDP and NG prices show cyclic. The seasonality $(\mathbf{S t})$ is a periodic variation that has a constant length and can be easily recognized by observing its graphic representation. Because the changes it causes in timeseries data are constant over time, it is easy to deal with its effect by finding seasonality indicators for the corresponding time periods. A typical example of a seasonal timeseries is NG demand in winter months. The randomness (Rt) is the timeseries' property according to which the observations vary around a constant mean, have a constant variance, and are probabilistically independent. Observations do not trend upwards or downwards, the variance does not increase overtime, the observations do not tend to be bigger in some periods than in other periods.

In the additive decomposition model the real values of the timeseries for each period are considered as the sum of the four components and are created in the following way: $\mathbf{Y t}=\mathbf{T t}+\mathbf{S t}+\mathbf{C t}+\mathbf{R t}$.

In the Multiplication Decomposition Model (MDM) the real values of the timeseries are determined by the product of the four components, ie as follows: $\mathbf{Y t}=\mathbf{T t} * \mathbf{S t} * \mathbf{C t} * \mathbf{R t}$.

Of the above two models, the additive model is used less frequently in practice because it is difficult to analyze it for computational reasons, and we will use multiple decomposition.

$3^{\text {rd }}$ : Autoregression Move Average models (ARIMA): They are stochastic mathematical models used to describe the overtime evolution of a physical quantity. They include the random error or prediction error, the size values that appear at previous times, and other stochastic factors. ARIMA models have been extensively studied by G. Box and G Jenkins to the extent that their names are almost synonymous with ARIMA procedures and their applications in the timeseries analysis and predictions. The Box and Jenkins proposed a family of algebraic prediction models from which we can select the most suitable for our timeseries. The ARIMA models based on multiple linear regression are described by the equation: $\boldsymbol{Y}_{\boldsymbol{t}}=$ $\boldsymbol{b}_{o}+\boldsymbol{b}_{1} \boldsymbol{X}_{1}+\boldsymbol{b}_{2} \boldsymbol{X}_{2} \ldots \ldots \boldsymbol{b}_{p} \boldsymbol{X}_{p}+\boldsymbol{e}$, where $\mathbf{Y}$ is the dependent variable and $\boldsymbol{X}_{1}, \boldsymbol{X}_{2}, \ldots, \boldsymbol{X}_{p}$ are the independent variables and are values of the timeseries in previous periods. Also, the ARIMA models express $\boldsymbol{Y}_{\boldsymbol{t}}$ as a linear function of the p's of real past values of $\boldsymbol{Y}_{\boldsymbol{t}}$ and the independent variables $\boldsymbol{X}_{1}, \boldsymbol{X}_{2}, \ldots, \boldsymbol{X}_{\boldsymbol{p}}$, are the values of the errors of previous periods as the difference of predicted values from the actual prices. These models can only be used for stationary timeseries, not for nonstationary ones. The "white oise" model is expressed as ARIMA (0,0,0) while the "random-walk" model is expressed as ARIMA $(\mathbf{0 , 1 , 0 )}$. The main things related to ARIMA are:

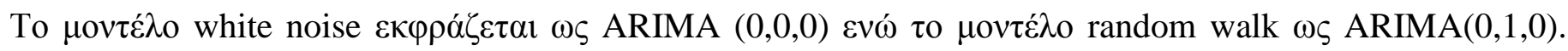
The main remarks related to ARIMA are:

○ The rk Auto-correlation coefficient indicates the correlation of the timeseries with itself for observations that are distant from each other and is defined as: $\boldsymbol{r}_{\boldsymbol{k}}=\sum_{1}^{\boldsymbol{n}-\boldsymbol{k}}\left(\boldsymbol{Y}_{\boldsymbol{t}}-\boldsymbol{Y}_{\boldsymbol{t}}\right)\left(\boldsymbol{Y}_{\boldsymbol{t}-\mathbf{1}}-\right.$ $\left.\dot{Y}_{t-1}\right) / \sum_{1}^{n}\left(Y_{t}-\dot{Y}_{t}\right)^{2}$

$\circ$ In a random timeseries, the $95 \%$ of the autocorrelation coefficients are in the range defined by the values $\pm \sqrt{(1.96 / n)}$ where $\mathrm{n}$ is the number of observations. 
- The coefficient of partial autocorrelation of class $\mathbf{k}$ is denoted by $\boldsymbol{a}_{\boldsymbol{k}}$ and can be calculated by applying the method of multiple linear regression with dependent variable $\boldsymbol{Y}_{\boldsymbol{t}}$ and independent variables $\boldsymbol{Y}_{t-1}, \ldots, Y_{t-k}: Y_{t}=b_{o}+b_{1} Y_{t-1}+b_{2} Y_{t-2} \ldots . b_{k} Y_{t-k}$

○ The "Sliding Operator" $\mathbf{B}$ has no other mathematical meaning than to facilitate the writing of the different types of models that would otherwise be very difficult to be expressed. The "Sliding Operator" is defined as $\boldsymbol{B}_{\boldsymbol{\kappa}} \boldsymbol{Y}_{\boldsymbol{t}}=\boldsymbol{Y}_{\boldsymbol{t}-\boldsymbol{k}}$ that is, when an observation is multiplied by the operator, then this results in the observation before k-time moments, where $\mathrm{k}$ is the exponent of the operator.

We considered worthy to present in tabular form the key-determinants of electricity and NG demand in various countries in weighted average term and how different they are.

Table 1: analysis of t determinants of electricity and NG demand and consumption

\begin{tabular}{|l|l|l|}
\hline Determinants influencing electricity and NG & Electricity \% & Natural gas (NG) \% \\
\hline GDP/capita & 64,2 & 67,8 \\
\hline Structure of GDP & 48,7 & 63,2 \\
\hline Price of electricity and NG & 72,4 & 61,7 \\
\hline Weather & 33,4 & 50,2 \\
\hline Unemployment \% & 12,4 & 8,9 \\
\hline Existed infrastructure for NG use & 34,2 & 46,3 \\
\hline Electricity and NG retailers promotion policies & 24,8 & 35,9 \\
\hline $\begin{array}{l}\text { Sources: Hodroyiannis 2004, Sanchez-Ubeda and Berzosa 2007, Behrouznia A et al 2010, } \\
\text { Toksari 2010, Dombayci 2010, Okajima and Okajima 2013, Dergiades et al 2013 - proper } \\
\text { adaptations by authors }\end{array}$ \\
\hline
\end{tabular}

\section{Literature review on the issue of NG demand and consumption forecasting}

Natural Gas (NG) demand and consumption forecasting was investigated in several different areas, spatial level, time level, gas distribution system levels, sectoral levels- industrial, commercial, and domestic consumers, etc. In addition, there have been some studies on predictions at the giant individual customer level. The above researches proceeded to forecasts for various time horizons. Time horizons ranging from a few hours to a few or many years. Most of these studies, however, dealt with annual, three-year, and multiyear forecasts. The scientific community around the world has been predicting NG demand based on different models and forecasting methods. From very simple statistical models, such as timeseries models, and neural networks to econometric models and various more specialized methods.

Verhulst MJ (1950) studied the NG demand forecasting by the French industry in a sample of 46 companies divided into three groups. He built a model that was defined by the demand equation, the production equation, and the equilibrium equation between price and income. His model achieved rather a good accuracy. The accuracy is estimated via gap analysis, forecasting demand/actual demand X 100. The smaller result, the greater accuracy of model.

Hubbert M.K (1957) explored the life cycle of fossil fuels and establish the so-called "Hubbert curve model" of mathematical relationships included in the complete production cycle of any exhaustive resource and the production rate $\mathrm{dQ} / \mathrm{dt}$ as a function of time. His model achieved good to moderate accuracy.

Balestra P and Nerlove M (1966) used econometric methods in forecasting the NG demand by domestic and commercial sectors, based on the model of minimal squares. Their model achieved rather a good accuracy. Berndt E.R and Watkins GC (1977) used econometric methods in forecasting the NG demand by domestic and commercial sectors of Columbia and Ontario, based also on the model of minimal squares. Their model achieved good accuracy.

Piggott J.L (1983) predicted the NG demand in sectoral daily and weekly basis in five countries using Box- 
Jenkins modeling. His model achieved moderate to good accuracy.

Herbert J.H (1987) used Multiple Regression Modeling Methods to assess the overall monthly industrial demand for NG in the United States. Their model achieved rather a good accuracy.

Werbos P.J (1988) studied a Generalized Back-Propagation application in predicting NG demand in emerging energy markets. His model achieved good accuracy.

Brown R.H et al(1994/1995) developed models based on Feed-Forward ANN to predict NG consumption by households on a daily basis in Wisconsin, USA. Their model achieved a good accuracy.

Smith P et al (1996) used expert systems to predict NG demand and compared their results with them come by traditional forecasting methods.

Bartels R et al (1996) used the statistical method Conditions Demand Analysis (CDA) to calculate the consumption of NG in Australia. Their model achieved good accuracy.

Sailor D, Munoz R (1997) They developed a methodology for assessing the sensitivity of electricity and NG consumption in an area to existed environmental conditions. Their model achieved good accuracy.

Khotanzad and Elragal H (1997) used a combination of ANN forecasters for prediction of NG demand and consumption in different areas. Their model achieved good accuracy.

Al- Fattah SM and Startzman RA (2000) predicted the NG global demand for the next fifty years using an approach to the Multicyclic Hubbert Model with moderate results.

Gumrah F et al (2001) used the idea of the "Degree-Day Model" to model NG demand in sectoral basis to Ankara / Turkey with moderate results.

Siemek et al (2003) used an adaptation of the "Hubbert Model" to predict NG consumption in Poland over the next forty years with moderate TO good results.

Gorucu FB et al (2004) developed a Multi-Linear Regression model to identify the factors influencing NG demand in Ankara and to predict consumption using optimistic and pessimistic scenarios with moderate to good results.

Gil S and Deferrari J (2004) presented a Generalized Model for forecasting the domestic and commercial consumption of NG in urban areas, in the short and medium term forecast horizon, day-ahead up to five years with moderate to good results with moderate to good results .

Elgaral H (2004) proposed a new technique to improve ANN forecasting ttechniques using the "FuzzyGenetic" model with good results.

Gutierrez R et al (2005) tested the capabilities of the "Gompertz-type Innovation Diffusion Process GIDP" as a reliable stochastic model for predicting increased NG consumption in Spain with good results.

Potocnik et al (2007/2008), proposed an energy forecasting approach where energy consumption cycles are analyzed, and the information obtained are incorporated into the statistical forecasting model. They studied practices for the construction of models with an explanatory example of the Slovenian economic model that motivates NG distributors to predict their future consumption with the least error delivering the results to a responsible entity. The results were significant satisfactory.

Aras N (2008) introduced an application of Smart Genetic Algorithms to predict the short-term demand of NG by domestic consumers with rather good success.

Jiang et al (2008) investigated three Chinese areas Peking, Guang-Dog and Shanghai, identifying the most important factors leading to NG consumption. Using the MARKAL optimization model, they showed that the NG consumption level is the most sensitive to restrictive scenarios. with rather good success.

Vondracek $\mathbf{J}$ et al (2008) presented an OLS statistical approach to forecast NG consumption by individual domestic and small commercial customers with very success.

Aydinalp - Koksal M and Ugursal VI (2008) studied the Conditional Demand Analysis CDA method to model end-use energy consumption by domestic consumers in Canada with very success. 
Ma H $\kappa \alpha$ Wu Y (2009) used a dynamic "Gray Model” to predict NG consumption in China from 2008 to 2015 with satisfactory results.

Xie Y and Li M (2009) introduced the "Gray Model" optimized with Genetic Algorithms to predict NG consumption in new energy markets with satisfactory results.

Azadeh A et Al (2010) introduced the "Adaptive Network-Based Fuzzy Inference System" (ANFIS) to assess NG demand in Iran using daily consumption data with moderate to good results.

Xie Y and Li M (2009) analyzed NG reserves, distribution system and the sectoral using in China, and predicted the future consumption using the generalized "Weng" and "Gray Model" models with satisfactory results.

Xu G каı Wang V (2010) used the "Polynomial Curve and Moving Average Combination Projection PCMACP" model to calculate future NG consumption in China from 2009 to 2015 with moderate to good results.

Erdogdu E (2010/2012/2014) focused on demand characteristics, assessed the short-term and long-term price and revenue elasticities of each NG sector in Turkey, and predicted in 3 different years its future growth using an ARIMA model with good accuracy.

Aramesh A at al (2014) used a general neural and fuzzy-neural algorithm aiming to forecast with great accuracy the NG gas demand in city- gate stations with satisfactory results.

Nick S, Thoenes S (2014) suggested a method to investigate the determinants of what drives natural gas prices in every region or country using a structural VAR approach with satisfactory results.

Azadeh et al (2010/2012/2014/2015) proposed alternative approaches of the «Adaptive Network Based Fuzzy Inference System - Fuzzy Data Envelopment» models for predicting and analysis of NG demand in combination with Neuro-Fuzzy Inference Approach with moderate to good results.

Jiang L.Y (2014) suggested a forecasting model to predict NG gas based on "improved back propagation neural network" with satisfactory success.

Platts I (2016) suggested a methodology and speciation's guide for European natural gas assessments and indices and this guide is used by many energy decision-makers

Lilian M de Menezes at al (2018) investigated the link between the UK natural gas market, and other energy markets, using multivariate GARCH models and data from the spot markets at daily frequency, from January 2000 to May 2015. The proposed bivariate BEKK model allow for spillovers and interactions among energy markets, asymmetries, and dynamics in the fundamental values, as proxied by the interestadjusted spread between spot and futures prices.

\section{Implementation of our models and dataset in timeseries form used}

The basic steps toward the solve of our problem are:

o The gathering of overtime 1999-2018 data in timeseries form for the two regions of Attica and Thessaly concerning their total and per capita GDP, electricity, and NG demand/consumption. The same data-exempt NG demand- was collected for the region of EMTH where its citizens predicted to connect with the NG network at the end of 2022.

- Initial approach to define the type of timeseries makes up our datasets through descriptive statistics

- Selection and implementation of seven deterministic forecasting models and their trialed running in order to be checked their functionality.

○ Final running the seven deterministic forecasting models with S/W packages SPSS, FORECAST, EVIEWS, WDI

- Saving the prices of the forecasts for their evaluation regarding their accuracy using the four statistical residuals or errors, Mean Squared Error-MSE, Root Mean Squared Error-RMSE, Mean Absolute Percentage Error-MARE, Mean Percentage Error-MPE, 
- Calculation and estimation of errors of each model separately.

- Evaluation and comparison of methods based on errors and ranking them according to their accuracy and reliability.

\section{Reasons for our correct choice the rather best model}

We studied in deep the data before we run the model and interpret results. If we did not do that the results could be strongly driven by outliers and this is especially true for models that minimize denuded squared sums.

We also spent a lot of time understanding the objective function of our models and how the data and models relate to the objective function.

We spent a lot of time understanding dataset and models characteristics and we formed a hypothesis which models are likely to best capture those characteristics. Although the model fanciness, we could forget the dumb way of forecasting data and error metrics are decreasing. Without using many forecasting models and benchmark them, we couldn't have a good absolute comparison for how good our models are. It is explained why we used seven forecasting models, starting from simpler -MA and going ahead with more complicate-ARIMA and then we compare their results using five criteria.

We started working with a small representative sample of total data of timeseries and we saw if we can get something useful out of it.

When we run the seven models in prediction, they get fed with data that is available when we run the model. That data might be different than what we assumed to be available in testing. We made sure that we run our model in realistic out-sample conditions and we understood when it will perform well and when it does not. We made sure you have a true test set free of any leakage from dataset. Especially beware of any timedependent relationships that could occur in NG demand and use.

We generated test such those accurately reflect data on which we would make predictions. Especially with our timeseries data we likely will have to generate custom cross-validation data or do roll-forward testing.

After we have finished building the model, we tried to find another version of the datasets that could be a surrogate for a true out-sample dataset.

\section{Descriptive statistical analysis}

The basic data for the region of EMTH are the follow:

Table 2: basic data describing the energy and economic structure of REMTH

\begin{tabular}{|l|l|}
\hline Descriptive data of region & Quantity \\
\hline Total population & 608.511 \\
\hline Number of families & 324.515 \\
\hline Number of buildings & 264.167 \\
\hline Houses & 187.310 \\
\hline Hotels every type & 1.024 \\
\hline Manufacturing buildings & 1.739 \\
\hline Schools every level & 1.577 \\
\hline Premises and offices & 9.995 \\
\hline Hospitals and clinics & 125 \\
\hline Various & 61.397 \\
\hline Average total energy consumption per family in KWh & 13.994 \\
\hline Average electricity consumption per family in KWh & 3.750 \\
\hline
\end{tabular}




\begin{tabular}{|l|l|}
\hline Average heat-oil consumption per family in KWh & 10.994 \\
\hline $\begin{array}{l}\text { Estimation of the number of total buildings with strong probability to be } \\
\text { connected to NG network }\end{array}$ & 211.334 \\
\hline
\end{tabular}

Source: HELLASTAT adhoc editions 2001-2020

The tables below gives the necessary and efficient data to make the predictions.

Table 3: overtime data in two Greek regions (Attika /Thessaly) related to NG demand/consumption

\begin{tabular}{|c|c|c|c|c|c|c|}
\hline Year & $\begin{array}{l}\text { Consumption } \\
\text { of NG in M3 }\end{array}$ & Users NG & $\begin{array}{l}\text { GDP total } \\
\text { in millions }\end{array}$ & $\begin{array}{l}\text { GDP/capita } \\
\text { weighted for } \\
2 \text { regions }\end{array}$ & $\begin{array}{l}\text { Energy KWh } \\
\text { consumption } \\
\text { /household }\end{array}$ & $\begin{array}{l}\text { Electricity } \\
\text { KWh } \\
\text { consumption } \\
\text { /household } \\
\end{array}$ \\
\hline 1999 & 14.000 & 15.800 & 70.250 & 13.985 & 14.856 & 4.322 \\
\hline 2000 & 14.800 & 16.400 & 71.684 & 14.084 & 14.982 & 4.120 \\
\hline 2001 & 18.200 & 19.300 & 77.031 & 14.966 & 14.654 & 4.352 \\
\hline 2002 & 33.450 & 34.200 & 84.098 & 16.728 & 14.987 & 4.532 \\
\hline 2003 & 46.500 & 47.900 & 92.377 & 18.482 & 14.876 & 4.423 \\
\hline 2004 & 82.850 & 83.200 & 101.212 & 20.242 & 15.346 & 4.236 \\
\hline 2005 & 122.200 & 123.000 & 104.269 & 20.756 & 15.564 & 4.122 \\
\hline 2006 & 151.800 & 152.800 & 115.548 & 22.882 & 15.345 & 4.098 \\
\hline 2007 & 198.600 & 200.800 & 123.760 & 24.724 & 15.122 & 4.087 \\
\hline 2008 & 215.000 & 218.100 & 128.903 & 25.521 & 15.008 & 4.124 \\
\hline 2009 & 308.700 & 309.000 & 130.815 & 25.534 & 14.987 & 4.002 \\
\hline 2010 & 238.700 & 239.900 & 121.297 & 23.767 & 15.001 & 4.108 \\
\hline 2011 & 461.500 & 463.000 & 110.925 & 22.421 & 15.230 & 4.020 \\
\hline 2012 & 492.800 & 495.700 & 102.188 & 19.362 & 14.874 & 4.234 \\
\hline 2013 & 522.100 & 525.800 & 96.527 & 19.371 & 14.465 & 4.356 \\
\hline 2014 & 540.300 & 544.500 & 95.161 & 19.287 & 14.201 & 4.567 \\
\hline 2015 & 556.300 & 559.800 & 93.669 & 19.102 & 14.123 & 4.543 \\
\hline 2016 & 574.600 & 577.000 & 98.886 & 19.101 & 14.765 & 4.632 \\
\hline 2017 & 589.200 & 602.400 & 95.129 & 19.574 & 14.806 & 4.652 \\
\hline $2018 *$ & 598.000 & 609.100 & 97.770 & 20.482 & 14.808 & 4.436 \\
\hline $2019 *$ & 608.000 & 612.400 & 100.339 & 22.153 & 14.862 & 4.286 \\
\hline
\end{tabular}

Table 4: overtime same data in Greek region EMTH related to NG demand/consumption exempt NG demand

\begin{tabular}{|c|c|c|c|c|c|c|}
\hline Year & $\begin{array}{l}\text { GDP } \\
\text { in } \\
\text { mil } €\end{array}$ & GDP/capita & $\begin{array}{l}\text { Total energy } \\
\text { consumption } \\
\text { KWH/household }\end{array}$ & $\begin{array}{l}\text { Electricity } \\
\text { consumption } \\
\text { KWh/household }\end{array}$ & $\begin{array}{l}\text { Energy } \\
\text { potentially } \\
\text { covered } \\
\text { by NG in } \\
\text { KWh }\end{array}$ & $\begin{array}{l}\text { Required } \\
\text { heating at } \\
\text { least } \\
\text { hours/day* }\end{array}$ \\
\hline
\end{tabular}




\begin{tabular}{|c|c|c|c|c|c|c|}
\hline Year & $\begin{array}{l}\text { GDP } \\
\text { in } \\
\text { mil } €\end{array}$ & GDP/capita & $\begin{array}{l}\text { Total energy } \\
\text { consumption } \\
\text { KWH/household }\end{array}$ & $\begin{array}{l}\text { Electricity } \\
\text { consumption } \\
\text { KWh/household }\end{array}$ & $\begin{array}{l}\text { Energy } \\
\text { potentially } \\
\text { covered } \\
\text { by NG in } \\
\text { KWh }\end{array}$ & $\begin{array}{l}\text { Required } \\
\text { heating at } \\
\text { least } \\
\text { hours/day* }\end{array}$ \\
\hline 1999 & 5.673 & 12.345 & 3.391 & 8.954 & 182 & \\
\hline 2000 & 5.789 & 10.075 & 12.383 & 3.396 & 8.987 & 178 \\
\hline 2001 & 6.280 & 10.701 & 12.456 & 3.402 & 9.054 & 183 \\
\hline 2002 & 6.686 & 11.316 & 12.864 & 3.765 & 9.099 & 165 \\
\hline 2003 & 7.206 & 12.146 & 13.005 & 3.912 & 9.093 & 181 \\
\hline 2004 & 7.611 & 12.772 & 13.234 & 3.954 & 9.280 & 169 \\
\hline 2005 & 7.868 & 13.142 & 13.065 & 3.863 & 9.202 & 193 \\
\hline 2006 & 8.141 & 13.535 & 12.986 & 3.802 & 9.184 & 185 \\
\hline 2007 & 8.906 & 14.741 & 12.764 & 3.754 & 9.010 & 180 \\
\hline 2008 & 9.450 & 15.568 & 12.312 & 3.456 & 8.856 & 177 \\
\hline 2009 & 9.306 & 15.272 & 12.763 & 3.546 & 9.217 & 176 \\
\hline 2010 & 9.198 & 15.057 & 12.543 & 3.402 & 9.141 & 183 \\
\hline 2011 & 8.150 & 13.320 & 12.238 & 3.322 & 8.916 & 185 \\
\hline 2012 & 7.579 & 12.403 & 12.432 & 3.356 & 9.076 & 167 \\
\hline 2013 & 7.003 & 11.498 & 12.685 & 3.413 & 9.272 & 174 \\
\hline 2014 & 6.878 & 11.324 & 12.652 & 3.410 & 9.242 & 175 \\
\hline 2015 & 6.831 & 11.281 & 12.386 & 3.387 & 8.999 & 178 \\
\hline 2016 & 6.901 & 11.432 & 12.368 & 3.298 & 9.070 & 166 \\
\hline 2017 & 6.946 & 11.539 & 12.543 & 3.345 & 9.198 & 164 \\
\hline $2018 *$ & 7.043 & 11.701 & 12.764 & 3.459 & 9.305 & 162 \\
\hline \multicolumn{7}{|c|}{$\begin{array}{l}\text { Source: HELLASTAT Special reports, DEH, RAE, DEDHE adhoc reports, EnergyPress } \\
\text { adhoc reports, www.oikonomiki.gr }\end{array}$} \\
\hline $\begin{array}{l}* \text { The } \\
\text { degree }\end{array}$ & 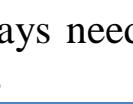 & the uce & eating & & es lower & an 8 Celsius \\
\hline
\end{tabular}

For the above timeseries we can calculate the values of variable parameters used in our measures extraction and are listed in next table 4 below:

Table 5: Transformation parameters used in feature measures

\begin{tabular}{|l|l|l|}
\hline Feature & $\begin{array}{l}\text { Raw time series data Yt- } \\
\text { RAW }\end{array}$ & $\begin{array}{l}\text { Trend and Seasonally Adjusted } \\
\text { data Ýt-TSA }\end{array}$ \\
\hline Serial Correlation & $2,7.53,0.125$ & $2,7.53,0.125$ \\
\hline Non-linearity & $1,0.069,2.311$ & $1,0.069,2.311$ \\
\hline Skewness & $1,1.510,5.991$ & $1,1.510,5.991$ \\
\hline Kurtosis & $1,2.273,11562$ & $1,2.273,11562$ \\
\hline
\end{tabular}


Periodicity

$1,12,52$

Continuing the descriptive statistics processing we result to the measures and indices of the following tables 6 and 7:

Table 6: Cross-correlation matrix

\begin{tabular}{|l|l|l|l|l|l|l|l|}
\hline $\begin{array}{l}\text { Statistical } \\
\text { indices }\end{array}$ & $\begin{array}{l}\text { NG MG MG Users } \\
\text { consumption }\end{array}$ & $\begin{array}{l}\text { Total } \\
\text { GDP in } \\
\mathbf{m}\end{array}$ & $\begin{array}{l}\text { Weighted } \\
\text { GDP/capita } \\
\text { for } \\
\text { regions }\end{array}$ & $\begin{array}{l}\text { Total } \\
\text { Energy } \\
\text { consumption } \\
\text { /household }\end{array}$ & $\begin{array}{l}\text { Electricity } \\
\text { consumption } \\
\text { /household }\end{array}$ & $\begin{array}{l}\text { NG } \\
\text { Consumption } \\
\text { per User }\end{array}$ \\
\hline $\begin{array}{l}\text { NG } \\
\text { Consumption } \\
\text { in M3 }\end{array}$ & 1.000000 & 0.999936 & 0.102020 & 0.191117 & -0.522102 & 0.409887 & 0.475341 \\
\hline NG Users & 0.999936 & 1.000000 & 0.098975 & 0.188759 & -0.522092 & 0.413696 & 0.471087 \\
\hline $\begin{array}{l}\text { Total GDP in } \\
\text { m }\end{array}$ & 0.102020 & 0.098975 & 1.000000 & 0.978134 & 0.367429 & -0.569617 & 0.661149 \\
\hline $\begin{array}{l}\text { Weighted } \\
\text { GDP/capita } \\
\text { for 2 regions }\end{array}$ & 0.191117 & 0.188759 & 0.978134 & 1.000000 & 0.336732 & -0.525691 & 0.685335 \\
\hline $\begin{array}{l}\text { Energy KWh } \\
\text { consumption } \\
\text { household }\end{array}$ & -0.522102 & -0.522092 & 0.367429 & 0.336732 & 1.000000 & -0.654082 & 0.052830 \\
\hline $\begin{array}{l}\text { Electricity } \\
\text { KWh } \\
\text { consumption } \\
\text { /household }\end{array}$ & 0.409887 & 0.413696 & -0.569617 & -0.525691 & -0.654082 & 1.000000 & -0.006266 \\
\hline $\begin{array}{l}\text { NG } \\
\text { Consumption/ } \\
\text { User }\end{array}$ & 0.475341 & 0.471087 & 0.661149 & 0.685335 & 0.052830 & -0.006266 & 1.000000 \\
\hline
\end{tabular}

Table 7: Descriptive statistics, basic statistical indices, and measures

\begin{tabular}{|l|l|l|l|l|l|l|l|}
\hline $\begin{array}{l}\text { Statistical } \\
\text { indices- } \\
\text { measures }\end{array}$ & $\begin{array}{l}\text { NG in M3 } \\
\text { consumption }\end{array}$ & NG users & $\begin{array}{l}\text { Total GPD } \\
\text { in m } €\end{array}$ & $\begin{array}{l}\text { Weighted } \\
\text { GDP/ } \\
\text { capita }\end{array}$ & $\begin{array}{l}\text { Total energy } \\
\text { consumption/ } \\
\text { household }\end{array}$ & $\begin{array}{l}\text { Electricity } \\
\text { consumption/ } \\
\text { household }\end{array}$ & $\begin{array}{l}\text { NG } \\
\text { consumption/ } \\
\text { household }\end{array}$ \\
\hline Count & 20.000000 & 20.000000 & 20.000000 & 20.000000 & 20.00000 & 20.000000 & 20.000000 \\
\hline Mean & 318.680000 & 321.715000 & 102.079400 & 20.426950 & 14.90030 & 4.296500 & 0.983216 \\
\hline Std & 228.251847 & 230.408763 & 15.973852 & 3.163026 & 0.35689 & 0.211692 & 0.022933 \\
\hline Min & 14.800000 & 16.400000 & 71.684000 & 14.084000 & 14.12300 & 4.002000 & 0.902439 \\
\hline 25\% & 112.362500 & 113.050000 & 94.764000 & 19.101750 & 14.79575 & 4.117000 & 0.980854 \\
\hline 50\% & 273.700000 & 274.450000 & 99.612500 & 19.908000 & 14.92900 & 4.261000 & 0.992889 \\
\hline 75\% & 544.300000 & 548.325000 & 112.080750 & 22.536250 & 15.03650 & 4.460000 & 0.994362 \\
\hline Max & 608.000000 & 612.400000 & 130.815000 & 25.534000 & 15.56400 & 4.652000 & 0.999029 \\
\hline $\begin{array}{l}\text { Pearson r } \\
\text { correlation }\end{array}$ & 0.0100 & 0.0150 & 0.0240 & 0.0310 & 0.0340 & 0.0420 & 0.0480 \\
\hline $\begin{array}{l}\text { Kendall } \\
\text { rank } \\
\text { correlation }\end{array}$ & 0.0080 & 0.0120 & 0.0220 & 0.0280 & 0.0360 & 0.0430 \\
\hline $\begin{array}{l}\text { Spearman } \\
\text { rank } \\
\text { correlation }\end{array}$ & 0.0080 & 0.0130 & 0.0230 & 0.0290 & 0.0340 & 0.0410 & 0.0490 \\
\hline
\end{tabular}


Corr_matrix $=N G \_c o n s . c o r r()$ corr_matrix

Table 8: Results of white noise from normal distribution of our timeseries concerning NG demand

\begin{tabular}{|c|c|c|c|c|c|c|c|c|}
\hline $\begin{array}{l}\text { Year/mea } \\
\text { sures }\end{array}$ & Kendall & Spearman & Pearson * & Kendall & Spearman & Pearson & $\begin{array}{l}\text { Order } \\
\text { Correlatio } \\
\text { n }\end{array}$ & $\begin{array}{l}\text { Entropy } \\
\text { Correlatio } \\
\text { n }\end{array}$ \\
\hline Year & Parametric & Parametric & Parametric & $\begin{array}{l}\text { Non- } \\
\text { Param } \\
\end{array}$ & $\begin{array}{l}\text { Non- } \\
\text { Param } \\
\end{array}$ & $\begin{array}{l}\text { Non- } \\
\text { Param } \\
\end{array}$ & & \\
\hline 1999 & 0.0080 & 0.0080 & 0.0100 & 0.0070 & 0.0060 & 0.0100 & 0.0100 & 0.0100 \\
\hline 2000 & 0.0120 & 0.0130 & 0.0150 & 0.0150 & 0.0140 & 0.0150 & 0.0160 & 0.0210 \\
\hline 2001 & 0.0220 & 0.0230 & 0.0240 & 0.0250 & 0.0260 & 0.0220 & 0.0240 & 0.0290 \\
\hline 2002 & 0.0280 & 0.0290 & 0.0310 & 0.0300 & 0.0290 & 0.0320 & 0.0310 & 0.0400 \\
\hline 2003 & 0.0360 & 0.0340 & 0.0340 & $\mathbf{0 . 0 3 7 0}$ & 0.0400 & 0.0390 & 0.0410 & 0.0550 \\
\hline 2004 & 0.0430 & 0.0490 & 0.0420 & 0.0480 & 0.0480 & 0.0440 & 0.0440 & 0.0640 \\
\hline 2005 & 0.0570 & 0.0600 & 0.0500 & 0.0600 & 0.0620 & 0.0510 & 0.0540 & 0.0760 \\
\hline 2006 & 0.0650 & 0.0690 & 0.0580 & 0.0680 & 0.0730 & 0.0590 & 0.0600 & 0.0810 \\
\hline 2007 & 0.0780 & 0.0760 & 0.0650 & 0.0800 & 0.0800 & 0.0690 & 0.0720 & 0.0930 \\
\hline 2008 & 0.0860 & 0.0880 & 0.0740 & 0.0920 & 0.0890 & 0.0810 & 0.0830 & 0.1010 \\
\hline 2009 & 0.0940 & 0.0980 & 0.0860 & 0.1040 & 0.1050 & 0.0890 & 0.0980 & 0.1160 \\
\hline 2010 & 0.1040 & 0.1020 & 0.0950 & 0.1150 & 0.1140 & 0.1020 & 0.1040 & 0.1270 \\
\hline 2011 & 0.1120 & 0.1100 & 0.1000 & 0.1260 & 0.1220 & 0.1090 & 0.1110 & 0.1390 \\
\hline 2012 & 0.1210 & 0.1240 & 0.1130 & 0.1340 & 0.1310 & 0.1170 & 0.1230 & 0.1490 \\
\hline 2013 & 0.1330 & 0.1380 & 0.1210 & 0.1390 & 0.1410 & 0.1280 & 0.1280 & 0.1600 \\
\hline 2014 & 0.1440 & 0.1480 & 0.1280 & 0.1430 & 0.1480 & 0.1380 & 0.1350 & 0.1700 \\
\hline 2015 & 0.1570 & 0.1530 & 0.1400 & 0.1490 & 0.1530 & 0.1460 & 0.1440 & 0.1780 \\
\hline 2016 & 0.1650 & 0.1660 & 0.1520 & 0.1540 & 0.1610 & 0.1560 & 0.1570 & 0.1880 \\
\hline 2017 & 0.1540 & 0.1580 & 0.1490 & 0.1370 & 0.1450 & 0.1320 & 0.1460 & 0.1790 \\
\hline 2018 & 0.1490 & 0.1400 & 0.1510 & 0.1370 & 0.1490 & 0.1410 & 0.1460 & 0.1810 \\
\hline \multicolumn{9}{|c|}{$\begin{array}{l}\text { figCorr, axCorr }=\text { plt.subplots }(\text { figsize }=(10,10)) \\
\text { sns.heatmap(corr_matrix, vmin=-1.0, vmax }=1.0, \mathrm{ax}=\mathrm{axCorr}, \text { annot=True, } \mathrm{cmap}=" \mathrm{YlGnBu} ") \\
\text { *Pearson } \mathrm{r} \text { correlation is the most widely used correlation statistic to measure the degree of the relationship between linearly } \\
\text { related variables }\end{array}$} \\
\hline
\end{tabular}

Further for more reliable and accurate predictions we have to take in account the elasticities of parameters we use in our timeseries. The elasticities for NG demand in Greece for the period under research have as the table below. It is noted that the same elasticities will be in force in the region of EMTH for plausible reasons.

\section{Table 9: elasticities for NG demand}

\begin{tabular}{|l|l|l|l|l|}
\hline Elasticity* & Period <12 months & Period <12 months & Period $>\mathbf{1 2}$ months & Period $>\mathbf{1 2}$ months \\
\hline Type of model & Logarithmic & Linear & Logarithmic & Logarithmic \\
\hline NG price/m3 & $-0,163$ & $-0,187$ & $-0,684$ & $-0,751$ \\
\hline
\end{tabular}




\begin{tabular}{|c|c|c|c|c|}
\hline Income per capita & 0,232 & 0,264 & 0,652 & 0,576 \\
\hline Cold days & 0,012 & 0,075 & 0,073 & 0,076 \\
\hline
\end{tabular}

From the above datasets in timeseries form we concluded to the follow results using statistical tools of descriptive statistics.

1. The tables show the correlation rank between the variables and are called Cross-Correlation matrices.

2. The correlation between variables is between -1 to 1 , so the Ha hypothesis is in force and the Ho one is rejected.

3. The diagonals of the table take values equal to the unit as it represents the correlation between the same variables

4. The outputs of the table are symmetrical with respect to the diagonals.

5. For the possible existence of a strong linear dependence between the interpretive variables, which would give us an erroneous estimate of the regression coefficients, as their dispersion increases, we perform a multicollinearity variability test. The results of E-Views are presented in the table and according to them the coefficients of linear dependence between GDP, GDP / capita and NG demand are quite close to the unit and therefore the interpretive variables of electricity prices are rejected.

6. According to the above analysis, we can conclude that the best adaptation is the non-parametric coefficients of Pearson and Spearman, ie they reject the Ho hypothesis as well as the level of significance.

\section{The generalized forecasting model adapted to each prediction method}

After all the above, we are led to the generalized form of the prediction model will take the formula $\mathbf{Y}_{\mathbf{t}}=\mathbf{b}_{\mathbf{o}}+\mathbf{b}_{\mathbf{1}} \mathbf{X}_{\mathbf{1}}+\mathbf{b}_{2} \mathbf{X}_{2} \ldots \ldots \mathbf{b}_{\mathbf{p}} \mathbf{X}_{\mathbf{p}}+\mathbf{e}$ which of course will give different values for each of the seven forecasting methods since both the residuals and the parameters of the independent variables Xt are differed. Also, they give different demand in $\mathbf{M}^{3}$ for different periods, since future NG users will install to NG network gradually, as it happens to other two regions. We adapt the timeseries real data to the generalized forecasting model that takes the final formula: $X_{t}=0.0046+0.35 X_{t+1}+0.38 X_{t+2} \ldots .0 .92 X_{t+20}+$ $\mathbf{e}_{\mathbf{t}}$ with an estimated standard deviation $\boldsymbol{\sigma}_{\boldsymbol{t}}=\mathbf{0 . 0 0 9 8}$. From the above generalized model and putting each time the different value of $\boldsymbol{e}_{\boldsymbol{t}}$, the outputs presented to the next table 8 were resulted.

Table 10: the NG demand separately for each forecasting method

\begin{tabular}{|c|c|c|c|c|c|}
\hline $\begin{array}{l}\text { Method/period from introduction NG - } \\
\text { demand in } M^{3}\end{array}$ & $\begin{array}{l}1^{\text {st }} \\
20 \% \\
\end{array}$ & $\begin{array}{l}5^{\text {th }} \\
65 \% \\
\end{array}$ & $\begin{array}{l}10^{\text {th }} \\
85 \% \\
\end{array}$ & $15^{\text {th }} 98 \%$ & $20^{\text {th }} \quad 100 \%$ \\
\hline \multicolumn{6}{|l|}{ Smoothing methods } \\
\hline Simple Moving Average (MA) & 45.663 & 137.367 & 179.634 & 207.107 & 228.315 \\
\hline Simple Exponential Smoothing (SES) & 43.467 & 134.256 & 174.345 & 204.784 & 217.334 \\
\hline Double Moving Average (DMA) & 42.983 & 132.875 & 171.652 & 201.651 & 214.902 \\
\hline Double Exponential Smoothing (B-DES) & 42.065 & 132.143 & 171.003 & 201.087 & 210.328 \\
\hline $\begin{array}{l}\text { Holt or Exponential Smoothing for Trend } \\
\text { Adaptation (H-ESTA) }\end{array}$ & 41.991 & 130.896 & 168.783 & 166.763 & 209.955 \\
\hline \multicolumn{6}{|l|}{ Decomposition methods } \\
\hline Multiplication Decomposition Model(MDM) & 41.345 & 131.086 & 169.207 & 166.206 & 206.728 \\
\hline \multicolumn{6}{|l|}{ Autoregression Average models } \\
\hline Autoregression Move Average & 41.667 & 131.387 & 170.207 & 166.765 & 208.339 \\
\hline
\end{tabular}




\begin{tabular}{|l|l|l|l|l|l|}
\hline $\begin{array}{l}\text { Method/period from introduction NG - } \\
\text { demand in } \mathrm{M}^{3}\end{array}$ & $\begin{array}{l}1^{\text {st }} \\
20 \%\end{array}$ & $\begin{array}{l}5^{\text {th }} \\
65 \%\end{array}$ & $\begin{array}{l}10^{\text {th }} \\
85 \%\end{array}$ & $15^{\text {th }} 98 \%$ & $20^{\text {th }} \quad 100 \%^{100 \%}$ \\
\hline (ARIMA) & & & & & \\
\hline
\end{tabular}

To evaluate the prediction accuracy of seven models we use as evaluating criteria the next five errors, Mean Squared Error-MSE, Root Mean Squared Error-RMSE, Mean Absolute Percentage Error-MAPE, Mean Percentage Error-MPE and Mean Absolute Deviation-MAD. Based on the five specific time horizons of the timeseries, the following results are obtained for the errors of the seven forecasting methods that we applied and more specifically for forecasts that concern the next periods.

Table 11: criteria used to evaluate separately each forecasting method using the errors method

\begin{tabular}{|l|l|l|l|l|l|}
\hline Method/criteria/period & MSE & RMSE & MAPE & MPE & MAD \\
\hline MA 1 ${ }^{\text {st }}$ period & -0.6472 & 9649.6 & 3.2 & 1,6 & 4.5 \\
\hline MA 2 ${ }^{\text {nd }}$ period & -1.3501 & 6258.1 & 1.8 & 1.1 & 4.3 \\
\hline SES $1^{\text {st }}$ period & -0.3054 & 8456.6 & 3.3 & 1.5 & 4.6 \\
\hline SES 2 ${ }^{\text {nd }}$ period & -1.0221 & 5986.1 & 2.2 & 1.0 & 4.4 \\
\hline DMA $1^{\text {st }}$ period & -0.3716 & 7345,4 & 3.1 & 1.8 & 4.2 \\
\hline DMA 2 ${ }^{\text {nd }}$ period & -1.2181 & 5343.3 & 2.0 & 1.1 & 3.9 \\
\hline B-DES $1^{\text {st }}$ period & -0.3126 & 9008.6 & 2.9 & 1.5 & 3,8 \\
\hline B-DES 2 ${ }^{\text {nd }}$ period & -1.0332 & 7145.8 & 1.7 & 0.9 & 3.5 \\
\hline H-ESTA $1^{\text {st }}$ period & $-0,0962$ & 8240.2 & 2.7 & 1.4 & 3.7 \\
\hline H-ESTA $2^{\text {nd }}$ period & -0.1160 & 6981.3 & 1.9 & 1.0 & 3.2 \\
\hline MDM $1^{\text {st }}$ period & -0.3125 & 7876.8 & 3.2 & 1.7 & 4,0 \\
\hline MDM 2 ${ }^{\text {nd }}$ period & -1.0346 & 6465.5 & 2.8 & 1.4 & 3.9 \\
\hline ARIMA $1^{\text {st }}$ period & -0.0072 & 5987.4 & 2.1 & 1.1 & 2.9 \\
\hline ARIMA 2 ${ }^{\text {nd }}$ period & 0.4780 & 4763.6 & 1.5 & 0.8 & 2.7 \\
\hline
\end{tabular}


All the above results and outputs are presented to the next figure 1.

\section{Critics and comments}
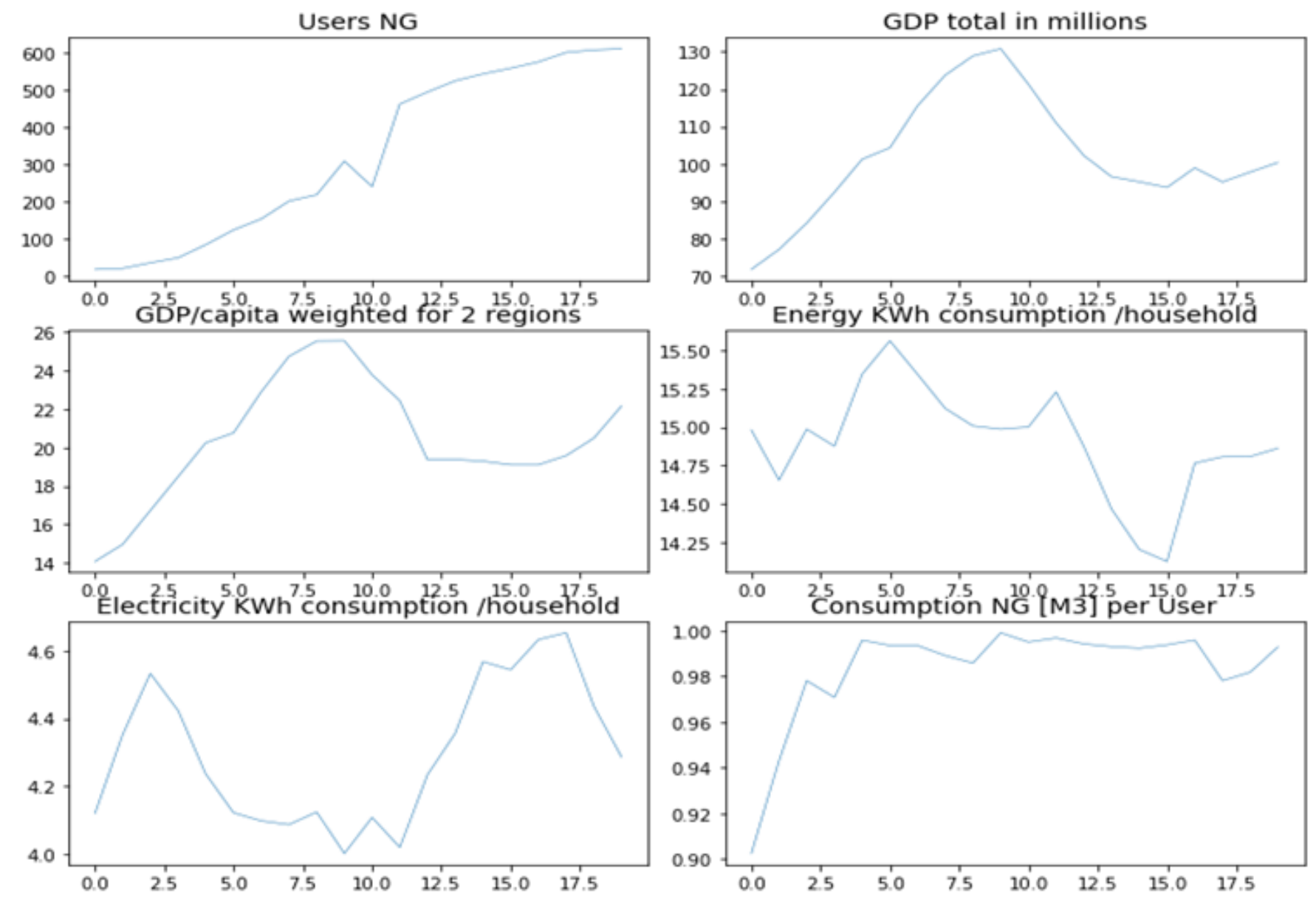

Figure 1: the results of models implemented

After above results and outcomes of the seven forecasting and evaluating models we conclude to:

- Based on the information of table 11, we can tell that the ARIMA method has $16.1 \%$ better accuracy performance than all the other six models. ARIMA model is better for producing predictions in future times for which we do not have historical data, as long as timeseries to be cleared from outliers.

- The second better method is the Multiplication Decomposition Model (MDM) which has 6.8\% better accuracy performance than all the other five models.

- It should be emphasized the importance of filtering the data of timeseries before producing forecasts. Usually in the initial data there will always be values which do not match the sizes of the neighboring values. A sharp increase or decrease in the values of the testable variable is something common for initial timeseries data, but not something acceptable in the science of predictions. This is because the accumulation of such prices can disorient the adaptation of timeseries models and give unreliable predictions. The same applies if there are empty prices in timeseries. In case the empty values cover a large size of the observations, specialized methods of intermittent demand, such as Croston methods, ADIDA are used, but in our case this was not necessary.

- Continuing the commentary of the results, the importance of filtering the data before the forecasting process has been particularly emphasized, especially when in the initial data there are valuesobservations which do not keep pace with the sizes of the neighboring values. It is obvious that in the case of processed and filtered data the improvement of the results are better by 12,6\%.

○ In order to be calculated the correlation measures among independent variables the next formulas were 
used:

\begin{tabular}{|l|c|}
\hline Measures & Formula \\
\hline Pearson's r & $r_{x y}=\frac{n \sum x_{i} y_{i}-\sum x_{i} \sum y_{i}}{\sqrt{n \sum x_{i}^{2}-\left(\sum x_{i}\right)^{2}} \sqrt{n \sum y_{i}^{2}-\left(\sum y_{i}\right)^{2}}}$ \\
\hline Spearman rank $\boldsymbol{\rho}$ & $\rho=1-\frac{6 \sum d_{i}^{2}}{n\left(n^{2}-1\right)}$ \\
\hline Kendall rank t & $\tau=\frac{n_{c}-n_{d}}{\frac{1}{2} n(n-1)}$ \\
\hline
\end{tabular}

\section{References}

[1.] Al-Fattah S.M, Startzman R.A (2000) "Forecasting world natural gas supply", Journal of Petroleum Technology, 52 (5), pp. 7-19.

[2.] Aramesh A, Ahmadi A (2014) "A general neural and fuzzy-neural algorithm for natural gas flow prediction in city gate stations", Energy and Buildings, 72, pp. 73-79.

[3.] Aras N (2008) "Forecasting residential consumption of natural gas using genetic algorithms", Energy Exploration and Exploitation, 26 (4), pp. 241-266.

[4.] Aydinalp-Koksal M, Ugursal V.I (2008) "Comparison of neural network, conditional demand analysis, and engineering approaches for modeling end-use energy consumption in the residential sector", Applied Energy, Volume 85, Issue 4, April 2008, pp 271-296.

[5.] Azadeh A, Asadzadeh S.M, Ghanbari A (2010) "An adaptive network-based fuzzy inference system for short-term natural gas demand estimation: Uncertain and complex environments" Energy Policy, Volume 38, Issue 3, pp 1529-1536.

[6.] Balestra P, Nerlove M (1966) "Pooling cross section and time series data in the estimation of a dynamic model: the demand for natural gas", Econometrica, 34(3), 585-612.

[7.] Berndt ER, Watkins GC (1977) "Demand for natural gas: residential and commercial markets in Ontario and British Columbia”, Canadian Journal of Economics, Canadian Economics Association, 10(1) pp 97-111.

[8.] Bartels R, Fiebig D.G, Nahm D (1996) "Regional end use gas demand in Australia", The Economic Record, 72 (219), pp. 319-331.

[9.] Behrouznia A, Saberi M, Azadeh A, Asadzadeh S.M, Pazhoheshfar P (2010), “An Adaptive Network Based Fuzzy Inference System-Fuzzy Data Envelopment Analysis for Gas Consumption Forecasting and Analysis: The Case of South America", In: International Conference on Intelligent and Advanced Systems, ICIAS. Article Number 5716160.

[10.] Brown R. H, Kharouf P, Feng X, Piessens L. P and Nestor D, (1994) "Development of feedforward network models to predict gas consumption" IEEE International Conference on Neural Networks - Conference Proceedings Volume 2, 1994, Pages 802-805.

[11.] De Menezes L.M, Russo M, Urga G (2018) " The volatility of natural gas prices in the United Kingdom market : drivers and spillover effects," The Energy Journal, 40(1), pp. 143-169.

[12.] Dergiades T, Martinopoulos G, Tsoulfidis L (2013) "Energy consumption and economic growth: Parametric and non-parametric causality testing for the case of Greece," Energy Economics, Elsevier, vol. 36(C), pp. 686-697.

[13.] Dombayci A (2010) "The prediction of heating energy consumption in a model house by using artificial neural networks in Denizli-Turkey", Advances in Engineering Software, 41(2), pp.141147.

[14.] Elragal H (2004) "Improving neural networks prediction using fuzzy-genetic model”, National Radio Science Conference, NRSC, Proceedings Volume 21, pp 393-400.

[15.] Erdogdu E (2010) “Natural gas demand in Turkey”, Applied Energy, Volume 87, Issue 1, pp 211219 
[16.] Gil S, Deferrari J (2004) “Generalized model of prediction of natural gas consumption”, Journal of Energy Resources Technology, Transactions of the ASME Volume 126, Issue 2, pp. 90-98

[17.] Gorucu F.B, Geris P.U, Gumrah F (2004) "Artificial neural networks modeling for forecasting gas consumption", Energy Sources, 26, pp. 299-307.

[18.] Gutierrez R, Nafidi A, Sanchez R.G, (2005) "Forecasting total natural-gas consumption in Spain by using the stochastic Gompertz innovation diffusion model", Applied Energy, 80 (2), pp115124.

[19.] Gumrah F, Katircioglu D, Aykan Y, Okumus S, Kilincer N (2001) "Modelling of gas demand using degree day concept: Case study of Ankara”, Energy Sources, 23(2), pp. 101-114

[20.] Herbert J.H (1987) "An analysis of monthly sales of natural gas to residential customers in the United States", Energy System and Policy, volume 10, pp. 127-147.

[21.] Hodrogiannis H (2004) "Estimating residential demand for electricity in Greece", Energy Economics, volume 26 (3), pp. 319-334.

[22.] Hubbert M.K (1957) "Nuclear Energy and the Fossil Fuels" Presented before The Spring Meeting of the Southern District Division of Production, American Petroleum Institute, San Antonio, TX, March 8, 1956. Publication No. 95.

[23.] Jiang B, Wenying C. Yuefeng Y, Lemin Z, Victor D (2008) "The future of natural gas consumption in Beijing, Guangdong and Shanghai: An assessment utilizing MARKAL" Energy Policy, Volume 36, Issue 9, pp. 3286-3299.

[24.] Imam A, Startzman R.A, Barrufet M.A, Hubbert M.K (2004) "Multicyclic Hubbert model shows global conventional gas output peaking in 2019”, Oil and Gas Journal, 102 (31), pp. 20-28.

[25.] Khotanzad A, Elragal H (1999) "Natural gas load forecasting with combination of adaptive neural networks", In: Proceedings of the International Joint Conference on Neural Networks Volume 6, pp. 4069-4072.

[26.] Ma H, Wu Y (2009) "Grey Predictive on natural gas consumption and production in China" Proceedings of the 2009 2nd Pacific-Asia Conference on Web Mining and Web-Based Application, WMWA 2009 2009, Article number 5232475, pp. 91-94.

[27.] Ma Y, Li Y (2010) "Analysis of the supply-demand status of China's natural gas to 2020", Petroleum Science Volume 7, Issue 1, pp. 132-135.

[28.] Nick S, Thoenes S (2014) «What drives natural gas prices? - A structural VAR approach», Energy Economics, volume 45, pp 517-527.

[29.] Okajima S \& Okajima H (2013) "Estimation of Japanese price elasticities of residential electricity demand, 1990-2007," Energy Economics, Elsevier, vol. 40(C), pp. 433-440.

[30.] Platts I (2016) "Methodology and speciation's guide - European natural gas assessments and indices", S\&P Global Platts. Available at https://www.platts. com/im.platts.content/methodologyreferences/methodologyspecs.

[31.] Piggott J.L (1983) "Use of Box-Jenkins modelling for the forecasting of daily and weekly gas demand", IEE Colloquium (Digest), (1983 /91), pp. 4-10.

[32.] Potocnik P, Thaler M, Govekar E, Grabec I, Poredos A (2007) "Forecasting risks of natural gas consumption in Slovenia", Energy Policy, 35, pp 4271-4282.

[33.] Potocnik P, Govekar E, Grabec I (2007) "Short-term natural gas consumption forecasting", Proceedings of the 16th IASTED International Conference on Applied Simulation and Modelling, ASM 2007, pp 353-357.

[34.] Potocnik P, Govekar E, Grabec I (2008), "Building forecasting applications for natural gas market", Natural gas research progress, New York: Nova Science Publishers, cop. 2008, pp. 505530.

[35.] Sailor D, Munoz R (1997) "Sensitivity of electricity and natural gas consumption to climate in the USA - methodology and results for eight states", Energy, 22 (10), pp 987-998.

[36.] Sanchez-Ubeda E.F, Berzosa A (2007) "Modeling and forecasting industrial end-use natural gas consumption”, Energy Economics, 29 (4), pp. 710-742.

[37.] Siemek J, Nagy S, Rychlicki S (2003) “Estimation of natural-gas consumption in Poland based on the logistic-curve interpretation", Applied Energy, 75 (1-2), pp. 1-7.

[38.] Smith P, Husein S and Leonard D.T (1996) "Forecasting short term regional gas demand using an 
expert system", Expert Systems with Applications, 10 (2): 265-273.

[39.] Toksari D (2010) "Predicting the Natural Gas Demand Based on Economic Indicators: Case of Turkey", Energy Sources Part A Recovery Utilization and Environmental Effects, 32 (6), pp. 559566.

[40.] Werbos P.J (1988) "Generalization of backpropagation with application to a recurrent gas market model”, Neural Networks, 1 (4), pp. 339-356.

[41.] Verhulst M.J (1950) "The theory of demand applied to the French gas industry" Econometrica 1950, 18(1,) pp 45-55.

[42.] Vondracek J, Pelikan E, Konar O, Cermakova J, Eben K, Maly M, Brabec M.A (2008) "Statistical model for the estimation of natural gas consumption", Applied Energy, Volume 85, Issue 5, May 2008, pp 362-370.

[43.] Xie Y, Li M (2009) "Research on prediction model of natural gas consumption based on Grey modeling optimized by genetic algorithm" Proceedings IITA International Conference on Control, Automation and Systems Engineering, CASE 2009 , Article number 5194459, pp 335-337.

[44.] Xu G, Wang W (2010) "Forecasting China's natural gas consumption based on a combination model”, Journal of Natural Gas Chemistry, 19, pp. 493-496. 